CuPAUAM. 18-1991, 211-225

\title{
PINTURAS ROMANAS PROCEDENTES DEL CONVENTO DE SAN PEDRO MARTIR (TOLEDO). ESTUDIO PRELIMINAR
}

\author{
Carmen Gutrai Pelegrin \\ UNIVERSIDAD DE ZARAGOZA
}

\begin{abstract}
Resumen
Se hace en este trabajo un primer análisis de la pintura romana aparecida en la excavación del convento toledano de San Pedro Mártir. A partir de los motivos decorativos y antes de proceder a su completa recomposición, se le atiibuye una fecha comprendida entre la segunda mitad del siglo I y comienzos del II d. C., con sus paralelos más cercanos en el repertorio ornamental romano-campano del s. I d. C.
\end{abstract}

\section{Summary}

This is a preliminary analysis of the Roman paintings discoered during the excavations in the monastery of San Pedro Mártir (Toledo). Based on the decorative motifs and before the final restoration is completed, they have been dated provisionally berween the second half of the 1 st and early 2 nd century AD. The closest parallel is the ornamental Roman-Campanian zepertoite of the 1st century AD.

Las pinturas romanas cuyo estudio preliminar realizamos aquí fueron descubiertas en el trascurso de las excavaciones arqueológicas dirigidas por el profesor Fernando Valdés en el convento toledano de San Pedro Mártir. Dichos trabajos formaron parte de la rehabilitación del antiguo complejo conventual, el más grande del casco urbano de la ciudad, integrado por veintiún edificios perfectamente diferenciados.

El hallazgo vio la luz el año 1989 durante el estudio del convencionalmente llamado Edificio 1 (1) (Fig. 1), construido, como demuestra su estructura arquitectónica después del llamado Claustro Real (2) (Fig. 2).

(1) El nivel del terreno excavado se encutentra por debajo de la inmediaza calle de San Clemenze, debajo de la que es previsible pudieran realizarse otros ballazgos semejantes, junto a la cara exzezior del muro conventual, de ampliarse la zona investigada.

(2) Debia estar ya terminado en 1571 


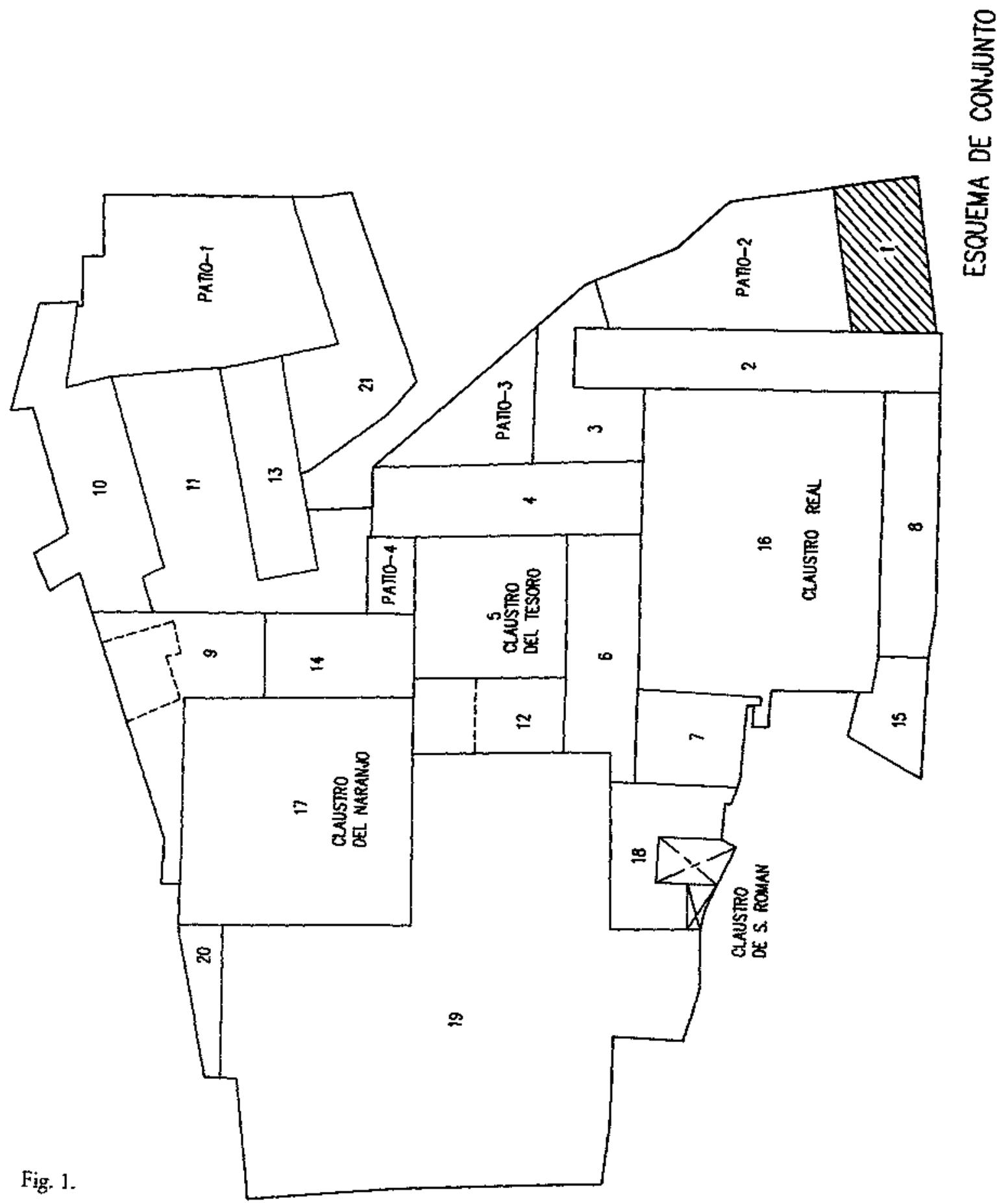




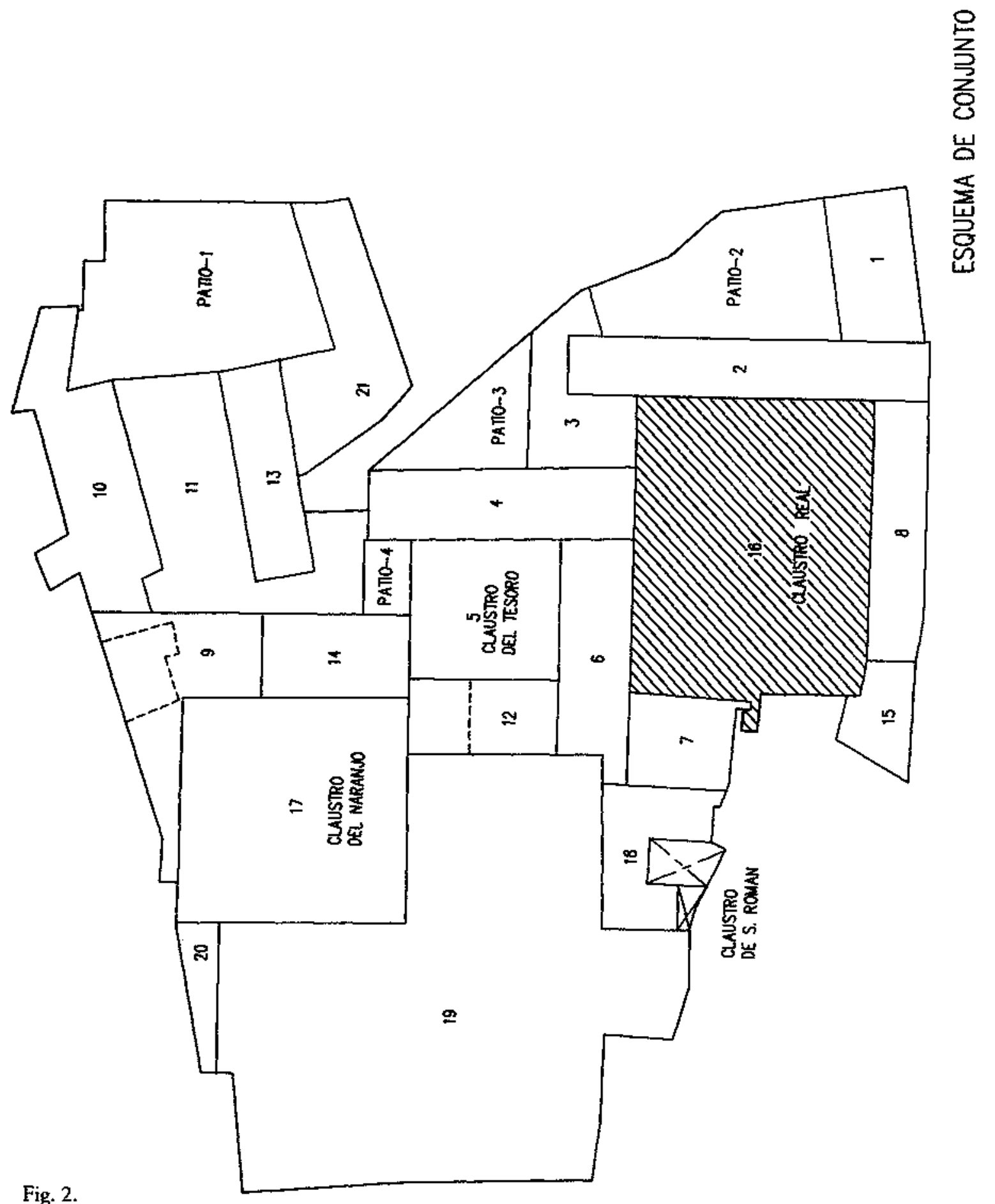

Fig. 2. 


\section{CARACTERISTICAS DEL HALLAZGO}

Con los datos que se desprenden de las planimetrías del Depósito 1 (3) es imposible conocer con seguridad si las pinturas decoraban el edificio en el que se hallaron o si fueron llevadas a ese lugat, utilizándolo como escombrera.

En cualquier caso, no podemos olvidar que los motivos que decoran los fragmentos de la capa B corresponden a la parte más alta de la pared y, por lo tanto, la primera en desprenderse, y los de la capa A pertenecen a la zona media y al zócalo, derrumbados a continuación, lo cual parece indicar la existencia de un orden de caída que sería imposible en el caso de una intervención extraña.

Los datos expuestos como características del hallazgo de las pinturas deberán compararse con los que ofrezcan los otros depósitos, con el fin de corroborar una u otra hipótesis.

\section{DESCRIPCION Y RESTITUCION HIPOTETTICA}

Con los fragmentos analizados, exhumados en el Deposito 1 podemos plantear la siguiente hipótesis de restitución de la pared:

- El zócalo, de fondo negro, está decorado con macizos vegetales de hojas naturalistas entre las que se disponen pequenas flores de color amarillo (Lám. Ib).

- La zona media está articulada en paneles anchos de fondo rojo, separados de los interpaneles negros por bandas azules. Los primeros, decorados ánicamente con un filere de encuadramiento interior de color blanco, y los interpaneles con candelabros de compleja articulacion (Lám. Ia). A tenor de los fragmentos conservados, éstos se componen de una sucesión de elementos figurados, de los que solamente conservamos los cisnes, en este primer depósito, que alternan con motivos vegetales, fundamentalmente roleos, y sirven de nexo de unión entre unos y otros (Lám. IIb). La decoración se completa con pequeños motivos colgados de lazos que deben nacer de los elementos antes citados. (Lám. Ila).

- La zona superior queda reducida a una estrecha banda negra, seguida de un friso que parece ser la imitación pintada de una cornisa de dentículos vista con una ligera perspectiva o bien el extremo de las trábeas de una viguería lígnea (Lám. Ilc).

\section{ANALISIS ESTILISTICO}

Puede afectar a diversos motivos aislados, así como al esquema general de la pared pintada.

\subsection{Macizos vegetales}

Este tipo de recurso ornamental aparece generalmente decorando el zócalo, si bien no debe olvidarse que será el trabajo de recomposición el que habrá de confirmar lo aquí planteado como hipótesis de trabajo.

En la pintura romana, este tipo de zócalo se articula de diferentes formas:

- Zócalo corrido decorado con macizos vegetales.

- Zócalo corrido decorado con macizos vegetales que se integran en escenas de caza.

- Zócalo dividido en compartimentos que encierran macizos vegetales.

- Zócalo compartimentado en el que alternan los macizos vegetales con otros motivos decorativos.

(3) El número de depósitos levantados es de cinco. 


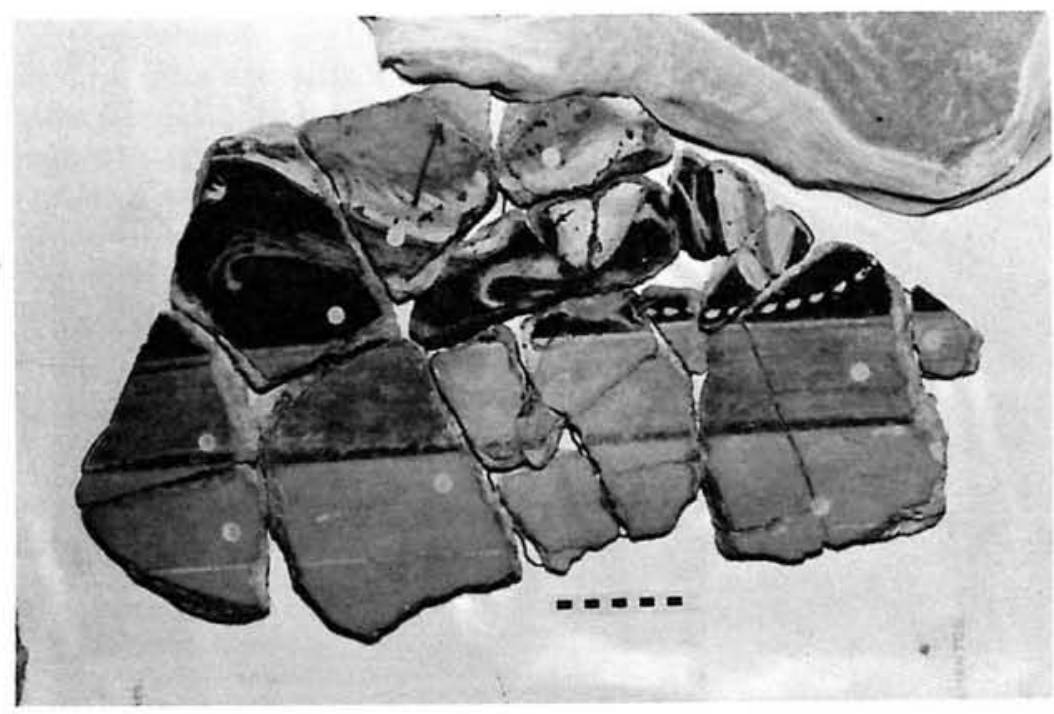

Lám. I a

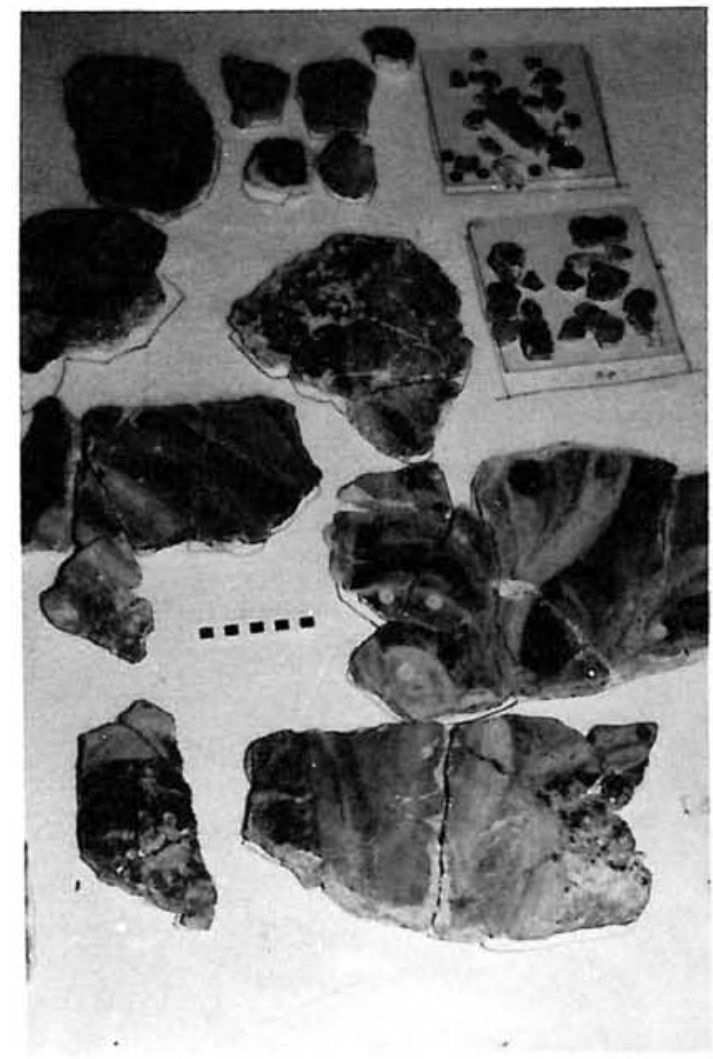

Lám. I b 


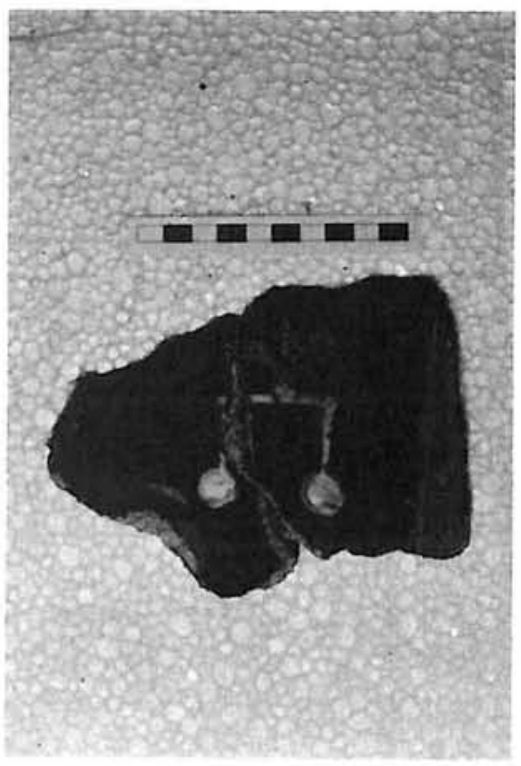

Lám. II a

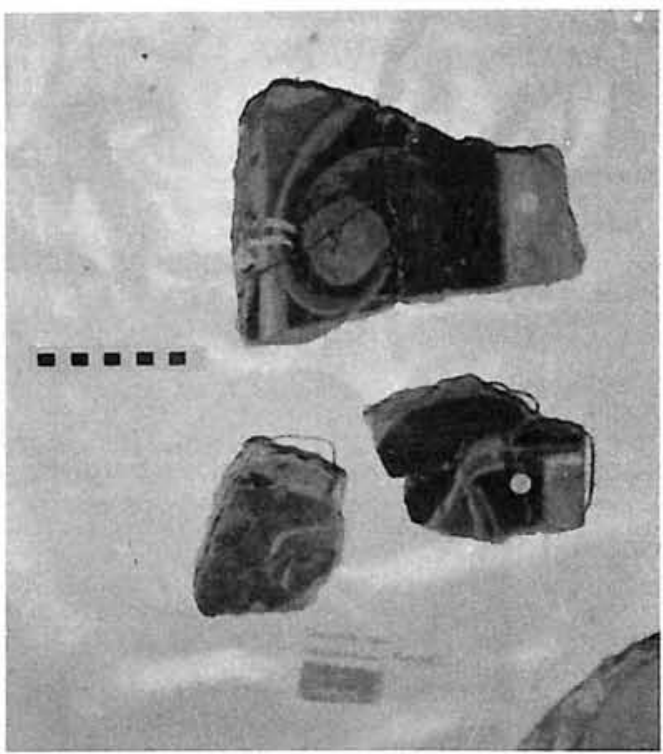

Lám. II b
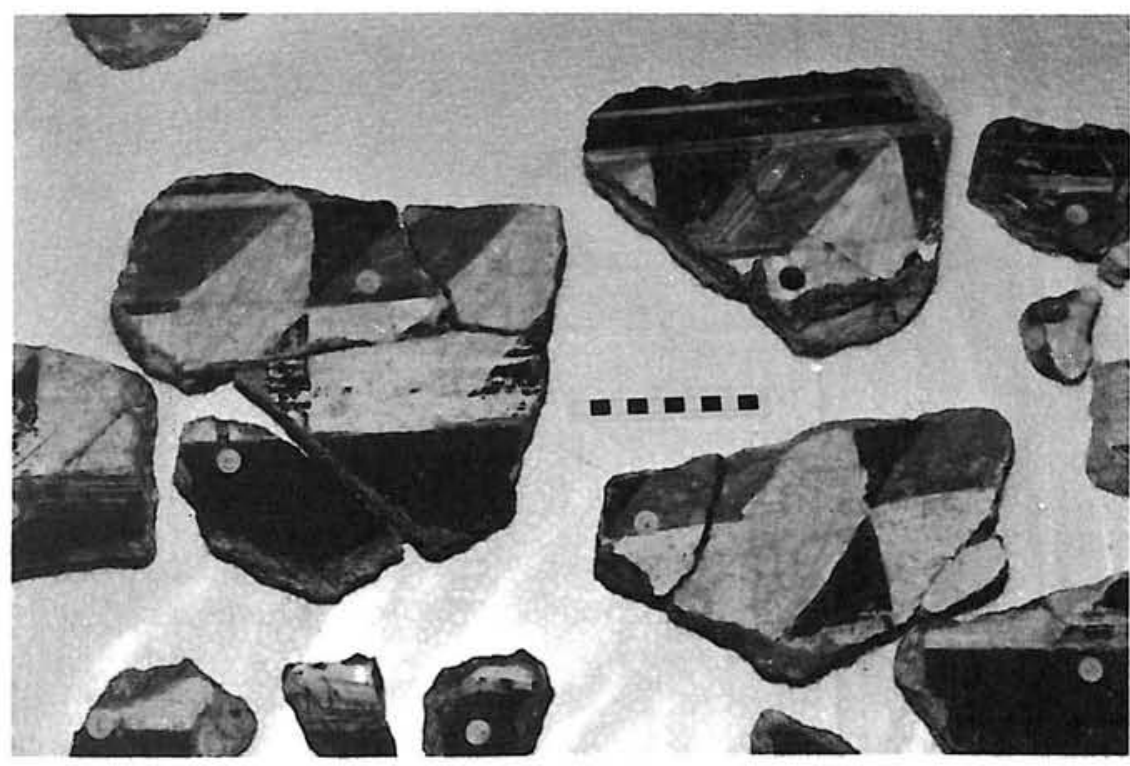

Lám. II c 
Con los fragmentos conservados y analizados hasta el momento, nos inclinamos por el ptimero de los tipos, ya que no existen restos de bandas de compartimentación ni otros motivos decorativos complementarios.

El inicio de estos tipos decorativos se encuentra en la fase Ic del estilo II en la Casa de Iulia Felix de Pompeya (II. 4. 2.) manteniéndose durante todo el período (4). Los ejemplos son múltiples en la pintura campana del III estilo (5) y se utilizan durante todo el IV siendo el motivo más utilizado en los zócalos de esta fase pictórica, de forma que sería interminable realizar un listado con todos ellos (6).

Por lo que se refiere al origen de este motivo, P. Grimal afirma que existe un primer estadio en el que se tiende a dar la ilusión de un jardf́n pintado más allá del muro, entre arquirecturas ficticias. Con la evolución de los sistemas decorativos se introducen elementos propiamente pictóricos, así lo que exa en origen una perspectiva es reemplazado por un símbolo, plantas en la zona baja del muro o árboles realizados a grandes trazos, de modo que la sugestión inmediata del jardín deja paso a simbolismos más extraños y complejos (7).

En el III estilo generalmente se sitúan en los compartimentos estrechos alternando con diferentes motivos en los anchos (cruces, rombos, tirsos con elementos colgantes) y así se comprueba en el triclinio del Termopolio I. 8. 8. de Pompeya (8). También pueden aparecer en un friso corrido, como en la Casa di Epidius Sabinus (IX. I. 22) (9), o en diferentes compartimentos, como sucede en el Edificio de Eumachia (10).

El IV estilo retoma idénticas estructuras, generalizándose los zócalos compartimentados en los que alternan las plantas con diferentes elementos. $\mathrm{La}$ articulación decorativa más utilizada es la división en compartimentos anchos, decorados con cenefas caladas y estrechos con macizos vegetales. En otros casos, igual que en el III estilo, las plantas decoran todo el zócalo, ya sea en diferentes compartimentos, como en la Casa di Cornelius Teges (I. 7. 11) (11), en Pompeya, y en la del Colonnato Tuscanico de Herculano (12), o en un friso corrido, como sucede en la Casa della Venere in Bikini (I. 11. 6), por citar sólo algunos de los ejemplos más significativos.

En el mundo provincial se constata la misma variedad que en la pintura campana. Además de las plantas que se integran en las escenas de caza como en Mercin-et-Vaux (13), en la Casa del Mitreo de Mérida (14), en la del Acueducto de Tiermes (15) y en el cortijo de Plaza de Armas del Pago de Bruñel (16), existen otras en las que los macizos vegetales alternan con zancudas, como en las pinturas de la casa con peristilo bajo las termas imperiales de Tréveris (17). En otros

(4) De Vos, M. (1975), p. 69.

(5) Baster, F. L. y De Vos, M. (1979), p. 122, noea 38.

(6) Recogeremos algunos de los ejemplos en los que los macizos vegetales son los únicos elementos decorativos.

(7) Grimal, P. (1969), pp. 233-241

(8) Bastet, F. L. y de Vos, M. (1979), lám. XIJ. 73.

(9) Ibidem, lasm. XXIV. 46.

(i0) Ibidem, lám. XVIII. 34.

(11) Maiuti, A. (1938), fig. 10.

(12) Manni, M. (1974), fig. 11.

(13) Barber, A. (1974), fig. 5.

(14) Abad Casal, L. (1976), Ifm Xla.

(15) Argence, J. L. y Mostalac, A. (1981), tám. 1 y (I985), 13m. IL.

(16) Nido, R. del (i964/65), fig. LVI. 2.

(17) Thomas, R (1984), p. 47. 
casos se combinan con tirsos cruzados como en la estancia 70 de la villa de St. Ulrich (18) o en el criptopórtico de Buchs (19). Sólo en la sala II de Soissons alternan con imitaciones de mármol (20). Todas ellas son de la segunda mitad del siglo I d. C.

Existen además, desde la primera mitad del s. I d. C., zócalos decorados únicamente con plantas en las pincuras procedentes de Lyon (21) y de Vienne (Place St. Pierre) (22), y se siguen representando en la segunda mitad del siglo, como constatamos en las pinturas de St. Ulrich (23) y en las de la Casa de Ninfeo de Bilbilis (Calatayud) (Guiral, C. 1990).

Resumiendo, podemos afirmat que este tipo decorativo no es un indicio de datación precisa, ya que se mantiene durante todo el s. I d. C.

\subsection{Candelabro}

Hasta que la recomposición de todos los fragmentos se haga efectiva, no podemos precisar con exactitud cual era el desarrollo del candelabro que decoraba los interpaneles. Sin embargo, a tenor de los fragmentos conservados, sí podemos afirmar que debió formarse por la superposición de diferentes motivos figurados y vegetales que apoyaban o nacían de un vástago central.

Este tipo de candelabro se integra claramente en la larga serie de candelabros provinciales que tienen su origen en el III estilo pompeyano y su máximo esplendor en el IV y que se desarrollan en las provincias en la segunda mitad del siglo I d. C. y comienzos del s. II. Su estudio fue abordado por A. Barbet, quién elaboró, además, una lista exhaustiva de sus principales características (24).

Del candelabro de Toledo contamos únicamente, por el momento, con parte de una plataforma circular donde se apoyan dos cisnes adosados. Estos están vistos de perfil, con las alas en posición heráldica y el cuello doblado, sujetando en su pico una cinta. Este tipo de representación del cisne es un tema que se repite constantemente en la pintura romana desde su aparición en la fase la del II estilo en la Casa de Augusto en el Palatino (25). Durante el III estilo aparece generalmente asociado a los candelabros, y se mantiene durante todo el IV estilo y en fases posteriores. Dentro del marco general de la pared puede estar en distintas situaciones, así podemos encontrarlo en el centro de un panel medio de color uniforme como en la Casa dei Vettii (VI. 15. 1) o en la de Pinarius Cerealis (II1. 4. 4); decorando el zócalo en la Casa di Sirico (VII. I. 25) y en la del Colonnato Tuscanico de Herculano y, finalmente, entre las arquitecturas ficticias de la zona superior, como en la Casa di Loreius Tiburtinus (II. 2. 2).

Son muchos los casos de la pintura romana en los que un cisne decora un candelabro, coronándolo o posado sobre volutas y zarcillos que nacen de un vástago. Los ejemplos que nás se asemejan al que estamos analizando son los procedentes de las Nymphéas de Vienne de época de Tiberio (26), de la Gertrudenstrasse de Colonia, de finales del s. I o comienzos

(18) Heckenbenner, D. (1984), p. 55.

(19) Drack, W. (1976), pp. 16 - 17.

(20) Defente, D. (1987), fig- 13.

(21) Heliy, B. (1980), pp. $10-12$.

(22) Barber, A. (1982), p. 63.

(23) Heckenbenner, D. (1985), pp. 14 - 15.

(24) Barber, A. (1981), pp. 47 - 83 y 60 - 70. Un análisis sobre los diversos candelabros haillados en Hispania en Abad Casal, L. (1982), pp. $288-296$.

(25) Cazeroni, G. (1983), fig. 12.

(20) Barbec, A. (1981), fig. 36 . 
del s. II (27), de la pared del Globo de Vienne (28) y de Tréveris (29), ambos sin datación precisa, pero que se integran en el grupo de candelabros anteriormente citado.

En la pintura hispana solamente un candelabro de las termas de Bilbilis (Calatayud), está coronado por un único cisne en la misma posición (30); sin embargo, en Astorga, pequefias palomas adornan los candelabros (31) y lo mismo sucede en Mérida, donde dos palomas descansan sobre dados situados en la parte superior de una de ellas (32).

Como puede comprobarse por los ejemplos expuestos, los candelabros con cisnes son típicos del s. I d. C., pero es a partir de la segunda mitad cuando su utilización se generaliza en las provincias y es en esta época donde debe encuadrarse el ejemplar de Toledo.

\subsection{Friso superior}

Este es el elemento menos común de las pinturas que estamos analizando, si bien, tampoco podemos afirmar que sea un unicum, ya que contamos con algunos paralelos que permiten su análisis estilístico.

El ejemplo más antiguo que conocemos procede de las pinturas de la Colonia Lepida Celsa (Velilla de Ebro, Zaragoza) fechadas hacia el año 40 a. C., en las que un friso de similares características corona una pared decorada con arquitecturas teatrales; ha sido interpretado como el extremo de una viguería lígnea (Mostalac, A., 1990). Ya del s. II d. C. son las pinturas de las estancias termales de Holstein en las que claramente se imitan los dentículos de una cornisa (33).

Como puede observarse, el margen cronológico es realmente amplio y todavía más si estudiásemos las pinturas procedentes de algunos yacimientos orientales, como Palmira, que se fechan ya a finales del s. III o IV y que presentan el mismo recurso ornamental (34).

En el caso que aquí estamos tratando, debemos considerar el friso como la copia de una cornisa denticulada y ponerlo en telación con los de la segunda mitad del siglo I que coronan las paredes de candelabtos y presentan diferentes ornamentos: imitaciones de flores de loto, de ovas o, simplemente, de cornisas molduradas.

\subsection{Esquema compositivo}

Ya hemos expuesto a lo largo de la descripción, que la articulación de la pared se resuelve en una alternancia de paneles anchos y estrechos y la únicas bandas corridas son las que forman el zócalo y el friso superior.

En general este tipo compositivo es ya característico de los inicios del III estilo, como podemos ver en la cella sepulcral de la Pirámide de Caio Cestio en Roma (35), y tiene un gran éxito

(27) Thormas, R. (1984), p. 48 y Scheilemacher, M. (1982), fig. 5. 17.

(28) Blanchet, M. (1913), fig. 5.

(29) Barbet, A. (1981), fig. 40.

(39) Guiral, C. (1986), fig. 1

(31) Luengo Martínez, J. M. (1956-1961), láms. CXXXIi - CXXXV

(32) Abad Casal, L. (1976), fig. 67b.

(33) Fuchs, M. (1984), pp. 66-67.

(34) Bartet, A. (1984), p. 80.

(35) Bastet, F. L. y De Vos, M. (1979), fig. 2. 
en la fase final de éste, como vemos en el atrio de la Casa di M. Lucretius Fronto (V. 4. a) (36), en el triclinio y en la exedra de la villa Pisanella (37), en el triclinio (i) de la Casa (VI. 14. 40) (38) y en el peristilo de la Casa del Citarista (I. 4. 5) (39). El esquema pasa al IV estilo convirtiéndose en uno de los tipos característicos, denominado por K. Schefold "Felderstil". Según este autor se fecharía en época de Vespasiano (40). W. J. Th Peters lo considera como una de las formas compositivas en las que se manifiesta el IV estilo, sin que puede adscribirse a una época determinada (41) y la misma concepción aparece en la obra de A. Barbet, en cuya tipologia corresponde al tipo 4 "paneles planos y candelabros" (42).

En la actualidad la teorfa de $\mathrm{K}$. Schefold no es admitida y, por tanto, la idea de que estas paredes son propias de la época de Vespasiano está totalmente desechada. Incluso se está delimitando una fase de transición entre el III y IV estilos, en la que se incluyen algunas paredes con este esquema decorativo (43) que, además, se considera utilizado desde el II estilo en las casas de segundo orden o en las estancias secundarias de las casas principales (44).

La fase pictórica del IV estilo presenta numerosas paredes pintadas bajo estos esquemas. En ellas se puede constatar la teorfa expuesta por V.M. Strocka ya que las encontramos en las estancias secundarias de casas muy importantes, como en la Casa dei Vettii (VI. 15. 1) (45), en la Casa degli Amorini Dorati (VI. 17. 7) (46), en la de Fabius Rufus (VII. 16. 22) (47), en la del Menandro (I. 10. 47) (48), en la del Príncipe di Napoli (VI. 15. 7) (49) o en la dell'Orso (VII. 2. 44-46) (50) y también en las casas más humildes, como en las situadas en la via Castricio, estudiadas por M. de Vos (51), en la Casa del Efebo (I. 7. 11) (52), en la del Centenario (IX. 8. 3) (53), o en la Casa del Bicentenario en Hetculano, entre otras muchas.

El esquema compositivo se mantiene en boga hasta el siglo $\mathrm{V}$ en Efeso (54), si bien con variaciones sustanciales que afectan fundamentalmente a los motivos decorativos, a los colores de fondo, uniformemente blancos, y al repertorio ornamental.

En la pintura provincial de la segunda mitad del siglo I d. C. se puede considerar el tipo compositivo predilecto, del que sólo son una excepción las pinturas de Tréveris (55), de Narbo-

(36) Ibidem, lám. XXXVIII. 52.

(37) Ibidem, láms. XXXIII y XXXIV. 61.

(38) Ibidem, lám. XXXV 63.

(39) $\mathrm{Tbidem}$, lam. 89.

(40) Schefold, K, (1949/1951), pp. 70 - 75; (1953/1954), pp. 114-115; (1962), pp. 133-139.

(41) Pezers, W J. Th. (1982), pp. 643-644.

(42) Bazber, A. (1985), pp. 201-202.

(43) Braganini, I. (1981), pp. 106-117.

(44) Son las denominadas “Neberzimmer" por W. Strocka (1975), pp. 10i-106.

(45) En Babber, A. (1985, fig. 27) se observa un plano completo que muestra los esquuemas diferentes de algunas estancias; Scheforld, K. (1962), láms. 130-131 y Pezers, W. J. Th. (1977), láms. 78, 83, 88, 89, 90 y 91

(46) Barbet, A. (1985), lám. VTb.

(47) Cerulli Irelli, G. (1981), fig. 9.

(48) Beyen, H. G. (1954), fig. 3.

(49) Srocka, W M. (1984), figs. 88-91.

(S0) Ehrhardz, W (1988), láms. $135-140$.

(5i) De Vos, M. (1981), figs. 2, 7, 9 y 13 .

(52) Maiuri, A (1938), fig. 10.

(53) Scheforhd, K. (3962), 13m. 115.

(54) Strocka, W M. (1977), figs. 125-130, 161-184, 224-230, 244-255, 280-311.

(5S) En Consancinsplazz (Steiner, P., 1917, pp. 56-59, figs. y Thomas, R., 1984, pp. 51-52), en Paltsplazz (Thomas, R; 
na (56) y de Mercin-et-Vaux (57) con tepresentaciones de arquitecnuras ficticias. La mayor parte de los conjuntos pictóricos se organizan en paneles anchos e interpaneles decorados con candelabros, como puede constatarse en Bonn (58), Colonia (59), Kempt (60), Maguncia (61), Tréveris (62), Virunum (63), Arcobriga (64), Astorga (65), Bilbilis (Guiral, C., 1990), Mérida (66), Aix-en-Provence (67), Arras (68), Bourges (69), Estrasburgo (70), Lyon (71), Narbona (72), St. Ulrich (73), Vienne (74), Elst (75), Nijmegen (76), Balaca (77), Boxmoor (78), Chester (79), Cirencester (80), Colchester (81), Fishbourne (82), Malton (83), Augst (84), Avenches (85), Munsingen (86) y Windisch (87).

Las pinturas de Toledo se integran perfectamente en este grupo provincial que se fecha en época flavia y ello no sólo por la articulación del esquema compositivo de la pared, sino también por la gama cromática (paneles rojos e interpaneles negros) y por el repertorio ornamental.

1984, p. 52) y en Gilberststrasse (Steiner, P., 1927, p. 60 y Thomas, R, 1984, p. 50).

(56) Sabrie, M. y R. y Solier, Y (1987), p. 191-204.

(57) Barbet, A. (1974), pp. 107-126.

(58) Thomas, R. (1984), p. 47

(59) Sur de la catedral, (Thomas, R. 1984, p. 47 y Linfert, A. 1975, fig. 48), Neumarter (Thomas, R., 1984, p. 48), Mungersciorf (Thomas, R, 1983. p. 80) y Gertrudenstrasse (Thontas, R, 1983, pp. 81-82, figs. 5. 2 y 3i Thomas, R, 1984, p. 48 y Scheilernacher, M., 1982, pp. 100-104).

(60) Parlaska, K. (1957), pp. 93-102, ḱms. 32-33 y Linfert, A. (1975), p. 16, fig. 3.

(61) Andersen, F. G. (1978/79), pp. 293-295, fig. 1 y láns. 56-57.

(62) Casa bajo las Termas Imperiales (Reusch, W., 1966, pp. 209-216, táms, 25-30) y Constantinsplatz (Thomas, R, 1984, pp. 47.48).

(63) Kenner, H. y Praschniker, C. (1947), pp. 196-197, !áns. II-iV

(64) Guiral, C. y Mostalac, A. (E.P.).

(65) Luengo Martinez, j. M. (1956/1961), pp. 167-171.

(66) Casa del Mitreo (Abad Casal, I., 1976, pp. 164-174).

(67) Barbet, A.; Guiral, C. y Nunes, R. (i990), pp. 35-57.

(68) Belot, E. (1984), pp. 12-15; (1986), pp. 62-63.

(69) Allag, C. y Le Bor, A. (1979), pp. 28-36.

(70) Pl. Kleber (Forrer, R, 1927, pp. 433-436, lams. LXII y LXiII).

(71) Maison du Char (VN AA., 1986, p. 26).

(72) Habización G. (Sabrie, M. y R. y Solier, Y., 1987, pp. 180-19t y 289-295).

(73) Esזarcia $\pi^{\circ} 89$ (Heckenbennex, D., 1983, pp. 123-135).

(74) Boussigues, M. (1878), pp. 156-159 y Blanchec, A. (1913), pp. 28-30.

(75) Bogaers, J. E. A. Th. (1955); Moormasn, E. (1982), p. 163.

(76) Peters, W J. Th. (1965/1966), pp. 130-132; Moormann, E. (1982), p. 163.

(77) Thomas, E. B. (1964), pp. 97-101; Frizot, M. (1981), pp. 262-264.

(78) Davey, M. y Ling, R. (1982), pp. 82-84,

(79) Davey, M. y Ling, R. (I982), pp. 96-97.

(80) Liversigde, J. (1982), pp. 75-76 y Davey, M. y Ling, R. (1982), p. 97

(81) lbidem pp. 99-101.

(82) $/$ bidem p. 116.

(83) lbidem, p. 145.

(84) Fuchs, M. (1989), p. 15.

(85) Drack, W. (1988), p. 28; Fuchs, M. (1989), pp. 50-53.

(86) Jbidem, p. 42.

(87) Drack, W. (1950), p. 121; (1988), p. 27 y Fuchs, M. (1989), pp. 50-53. 


\section{CONCLUSIONES}

Como ya hemos expuesto a lo largo de este estudio, las conclusiones que se derivan del análisis de estas pinturas son, en algunos casos, provisionales, en espera que la recomposición de los fragmentos y el estudio de los hallados en otros depósitos de la misma excavación permitan corroborar las hipótesis planteadas y ampliar los elementos de datación mediante el análisis estilístico de otros motivos decorativos.

A pesar de ello, no podemos finalizar sin exponer una breve sintesis de las conclusiones extraidas de su estudio.

Las planimetrías realizadas durante la excavación del Deposito I revelan la existencia de un cierto orden de caída, ya que es la zona superior de la pared la encontrada en el estrato inferiot, mientras que los fragmentos hallados en los superiores corresponden al zócalo y a la zona media, que, lógicamente se desprenden en último lugar. Todo ello parece indicar que las pinturas se hallan caídas en la misma estancia que decoraron.

Los motivos decorativos encuentran sus paralelos dentro del repertorio ornamental de la pintura romano-campana del s. I d. C. y se integran perfectamente dentro de la serie de pinturas provinciales de la segunda mitad del s. I y comienzos del s. II d. C. cuyos sus orígenes están el IV estilo.

En el marco de la pintura romana en Hispania, el conjunto de Toledo no sólo viene a llenar el vacío existente en el centro peninsular, sino que además se suma a los recientes estudios de pinturas de época flavia (Bilbilis, Calatayud, y Arcobriga, Monreal de Ariza) y se acerca a otras obras, tanto itálicas como provinciales que, hasta el momento, parecían ausentes en nuestro palis. 


\section{BIBLIOGRAFIA}

ABAD CASAL, L., 1976 "Pintira romana en Mérida". Augusta Emerita. Actas del Simposio Internacional conmemorativo del Bimilenario de Merida Madrid.

... 1982 Pintura romana en España. Universidad de Alicante - Universidad de Sevilla.

AilaG, C. y Le Bot, A., 1979 "La peinture murale gallo-romaine". Archéologie, 132.

ANDERSEN, F. G., 1978/79 "Eine tömische Wanddekoration aus Mainz". Mainzer Zeitschrift, 73-74.

ARgente, J. L. y Mostalac, A., 1981 "La pintura romana de la casa del Acueducto de Tiermes". Numantia, 1.

... 1985 "La construcción altoimperial denominada Casa del Acueducto de Tiermes (Tiermes, Soria)". Actas del XVII CNA. Logroho, 1983. Zaragoza.

BARBET, A., 1974 "Peintures murales de Mercin-et-Vaux (Aisne): Etude comparée". Gallia, 32.1.

... 1981 "Les peintures murales en place aux Nymphéas" Foundation E. Piot. Montuments et Memoires, LXIV.

... 1982 "La diffusion du III style pompéin en Gaule" Gallia, 40. 1.

... 1985 La peinture romaine. Les styles décoratifs pompeiens. Paris.

Barbet, A.; Gutral, C. y Nunes, R, 1990 "Aix en Provence, les fouilles de l'Aire du Chapitre (Salles 2 et 5)". Peinture Murale en Gaule. Actes du X Seminaire de l'AFPMA. Vaison la Romaine.

BarTeT, A., 1984 "Le Proche Orient", Archeologie. Les Dossiers. 89.

BASTET, F. L. Y DE VOS, M., 1979 II terzo stile pompeiano. Gravenhagen.

BELOT, E., 1984 La peinture murale romaine provinciale dans le Nord, Pas de Calais. Catalogue Exposition Valenciennes.

... 1986 "Les productions de l'artisanat pictural gallo-romaine à Nemetecum". Arras - Nemetecum et la partie méridionale de la cité des Atrévates. Catalogue d'exposition. Arras.

Beyen, H. G., 1954 "Die grüne Dekoration des Oecus am Peristyl der Casa del Menandro". Nederlands Kunsthistorich Jaarboek, 5.

BLANCHET, M., 1913 Etude sur la décoration des edifices de la Gaule romain. París.

BogaERS, J. E. A. TH., 1955 De gallo-romeise Tempels te Elst in the Over-Betuve. Gavenhagen.

Boussigues, M. 1878 "Peinture romaine de Vienne". Gazette Archéologique.

BragANTINI, I., 1981 "Tra il III e IV stile: ipotesi per una identificazione de una fase della pittura pompeiana". Pompei 1748 - 1980. I tempi della documentazione. Roma.

CARETTONI, G., 1983 "La decorazione pittorica della Casa di Augusto sul Palatino. RM., 90. 1.

Cerulus Irelu, G., 1981 "Le case di M. Fabio Rufu e di C. Iulio Polibio". Pompei 1748 - 1980. I tempi della documentazione. Roma.

Davay, M. y LiNG, R, 1982 Wall Painting in Roman Britain. Alan Sutton.

DEFENTE, D., 1987 "Peintures murales romaines de Soissons". Pictores per Provincias (Cabiers d'Archeologie romande, 43). Avenches.

DE VOS, M. 1975 “Scavi nuovi sconosciuti (I. 11. 13, I. 11. 12): piture memorande di Pompei con una tipología provvisoria dello stile a candelabri". MededRom, 37.

... 1981 "La bottega dei pittori de Via di Castricio". Pompei 1748 - 1980. I tempi della documentazione. Roma.

DRACK, W., 1950 Die Römische Wandmalerei der Schweiz. Basilea.

.. 1976 "Die römische Kryptoportikus von Buchs ZH und ihre Wandmalerei". Archäologische Führer der Schweiz, 7.

... 1988 Pittura parietale romana dalla Svizzera. Mendrisio.

Ehrhard, W. 1988 Casa del Orso (VII. 2. 44-46). (Häuser in Pompeji 2). Munich.

FORRER, R, 1927 Strasbourg - Argentorate. Estrasburgo.

Frizot, M., 1981 "Les peintures murales de Hongrie". $R A$. 
FuChS, M., 1984 "La Suisse”. Archeologie. Les Dossiers, 89.

... 1989 "Peintures romaines dans les Collections Suisses". Bulletin de Liaison, 9.

Grimal, P., 1969 Les jardins romains. París.

GurRal, C., 1986 "Pinnura romana procedente de las termas de Bilbilis". Resúmenes de Tesinas. Curso 1983 - 1984. Universidad de Zaragoza.

... 1990 Bilbilis. Decoración pictórica y estucos omamentales. Zaragoza. (Tesis Doctoral inédita).

Guirai, C. y Mostalac, A. (E. P.) "La pintura mural romana de Arcóbriga (Monreal de Ariza, Zaragoza) ${ }^{n}$. I Coloquio de pintura mural romana en Hispania Valencia-Alicante, 1989.

HeCKenbenneR, D., 1983 "Un decor architectural peint: la piece 89 de la ville 1 de Saint-Ulrich (Moselle)". Etudes d'Architecture Gallo-romaine. Nancy.

... 1984 "Les peintures murales de la villa gallo-romaine de Saint-Ulrich (Moselle): Etat de la question". Peinture mutale en Gaule. Actes des Seminaires de Limoges (1980) et Sarrebourg (1981) (Studia Gallica I). Nancy.

... 1985 Peintures murales romaines en Pays de Sarrebourg. Le perystile de la Ville de Saint-Ulrich. Catalogue Exposition. Sarrebourg.

Heliy, B., 1980 "Etude préliminaire sur les peintures murales gallo-romaines de Lyon". Peinture murale en Gaule. Actes des Séminaires. Dijon.

KenNeR, H. y PRASCHNIKeR, C., 1947 Der Bäderbezirk von Virunum. Viena.

LINFERT, A, 1975 Römische Wandmalerei der Nordwestlichen Provinzen. Colonia.

LIVERSIGDE, J., 1982 "Recents developments in Romano-British Wall Painting". Roman Life and Art in Britain (British Archaeological Reports, 41).

Luengo, MarTineZ, J. M., 1956/1961 “Astorga romana (Memoria del Plan Nacional 1954 - 1955)" NAH., 5.

Maruri, A., 1938 Le pitture delle case di M. Fabius Amandio, del sacerdos Amandus e di P. Cornelius Teges. (Mon. Pitt. An. Pompei II). Roma.

ManNi, M., 1974 Le pitture della Casa del Colonnato Tuscanico. (Mon. Pitt. An. Ercolano II). Roma.

MoORmanN, E., 1982 "Roman Wall painting in the Nederlands: A Survey". Roman provincial Wall Painting of the Western Empire (BAR International Series, 140). Oxford.

MOSTAlAC, A., 1990 Catálogo de la pintura romana y cornisas en estuco del Museo de Zaragoza: La Colonia Victrix Iulia Celsa. Zaragoza. (Tesis Doctoral inédita).

Nido, R. del, 1964/65 "Edificaciones romanas en el cortijo "Plaza de Armas" del Pago de Bruñel". $N A H, 8-9$.

Peters, W. J. Th., 1965/1966 "Mural Paintings Fragments found in the Roman Castra at Nijmegen". $B R O B$.

... 1977 "La composizione delle pareti dipinte nella Casa dei Vettii a Pompei". MededRom., 39.

... 1982 "La composizione delle pitture parietali di IV stile en Roma e in Campania". La regione sotterrata del Vesuvio. Studi e prospettive. Atti del Convegno Internazionale. Napoles.

Parlaska, K., 1957 "Wandmalereien". En KRAMER, W.: Cambodunumforschungen. Kalimuinz.

REUSCH, W., 1966 "Wandmalereien und Mosaikboden eines Peristylhauses in Bereich der Trierer Kaiserthermen". $\operatorname{Tr} Z, 29$.

SABRE, M. y R. y SOLIER, Y., 1987 La maison à portigues du Clos de la Lombarde à Narbonne et sa decoration murale (fouilles 1975 - 1983). RAN. Supp. 16.

SCHEILERMACHER, M., "Römische Wandmalerei in Köln". Roman provincial wall painting of the Western Empire (BAR International Series, 140). Oxford.

SCHEFOLD, K., 1949/1951 "Das Vespasianische Stil in Pompeji". BABesch., 24-25.

... 1953/1954 "Pompeji unter Vespasian. RM., 60 - 61.

1962 Vergessenes Pompeji. Berna - Munich. 
STEINER, P., 1927 "Römische Wandmalerei in Trier". TrZ, 2.

STROCKA, W. M., 1975 "Pompejanische Nebenzimmer". Neue Forschungen in Pompeji. Recklinghausen.

... 1977 Die Wandmalerei der Hanghäuser die Ephesos. (Forschungen in Ephesos VIII. 1). Viena.

... 1984 Casa del Principe di Napoli (VI. 2. 44-46). (Haiuser in Pompeji l). Tubinga.

Thomas, E. B., 1964 Römische Villen in Pannonien. Budapest.

THOMAS, R, 1983 "Neue Oberlegungen zur römische Wandmalerei von Köln". La peinture murale romaine dans les provinces de l'Empire. Jounées d'Etude de Parts (BAR International Series, 165).

Oxford.

... 1984 "Allemagne, Autriche et Hogrie". Archeologie. Les Dossiers, 89.

V. AA., 1986 jadis, rue Farges. Archeologie d'un quartier de Lyon antique. Lyon. 